\title{
The influence of separate-sex rearing on ostrich behaviour and skin damage
}

\author{
A. Meyer ${ }^{1,2, \#, ~ S . W . P . ~ C l o e t e ~}{ }^{3}$ \& C.R. Brown ${ }^{4}$ \\ ${ }^{1}$ Klein Karoo Agricultural Development Centre, PO Box 351, Oudtshoorn 6620, South Africa \\ ${ }^{2}$ School of Animal, Plant \& Environmental Sciences, University of the Witwatersrand, Private Bag 3, Wits 2050, South \\ Africa \\ ${ }^{3}$ Elsenburg Agricultural Development Institute, Private Bag X1, Elsenburg 7607, South Africa \\ ${ }^{4}$ Hartpury College (University of the West of England), Hartpury House, Hartpury, Gloucestershire, GL19 3BE, \\ England
}

\begin{abstract}
Separate-sex rearing of slaughter ostriches was investigated as a management strategy to minimize skin damage. Day-old ostrich chicks were divided into three treatment groups; a group of mixed-gender and two single-sex groups, one male and one female. At three months of age, because of the large variation in live weights, the birds were sorted within treatment according to weight. Each gender treatment was represented by six replications and each weight class treatment was represented by nine replications. At slaughter, chest circumference, slaughter weight, carcass weight, skin weight, skin area and skin grading were recorded. The only slaughter trait that was affected by gender treatment was skin weight without fat, with all-male groups having significantly heavier skins than all-female groups. Behavioural observations, carried out at nine and 13 months of age, indicated that aggression was more prevalent in all-male groups compared to all-female and mixed-gender groups. The all-female groups had the lowest levels of aggression. Diurnal time-activity budgets were largely unaffected by the gender composition of the groups. Evaluation of the skins at slaughter showed that kick marks on the area outside of the crown were more prevalent in allmale groups, indicating that increased aggression was associated with increased kicking behaviour which led to skin damage. However, because of the location of the kick marks, skin grading was not influenced. Weight class treatment also affected the prevalence of kick marks. Aggression and kick marks on the skin were generally more pronounced in the groups comprising the heavier chicks, suggesting that body weight may have an important effect on hormone levels and aggressive behaviour. Because of the general lack of improvement in the skin grading of the ostriches due to the increased skin damage in all-male groups when separated, it is concluded that the practice of separate-sex rearing has no definite benefits for slaughter ostrich production and product quality.
\end{abstract}

Keywords: Separate-sex rearing, ostrich behaviour, gender, skin damage, aggression

${ }^{\#}$ Corresponding author. E-mail: anelm@elsenburg.com

\section{Introduction}

Visible skin damage remains the single most important factor that determines the value of ostrich leather. There is, however, a shortage of scientific literature regarding related aspects, like ostrich skin quality (Sales, 1999) and behaviour (Deeming \& Bubier, 1999), and this lack of knowledge currently prevents us from finding effective solutions for minimizing damage to the skins of slaughter ostriches. Work on the behaviour of ostriches in farming environments has only recently begun (Deeming \& Bubier, 1999) and most studies focused on breeding ostriches. The behaviour of juvenile ostriches has received little attention and the few studies available did not differentiate between genders.

A better understanding of the behaviour of slaughter ostriches will help identify the origin of skin damage, since specific behavioural aspects are thought to contribute to such damage. This will enable the development of appropriate management practices that will minimize the occurrence of such injuries. In this regard, agonistic behaviour is clearly of significance because aggressive interactions can easily lead to skin injuries (Angel, 1996; Samson, 1996) and permanent skin damage (Meyer et al., 2003). According to Samson (1996) aggression amongst ostriches becomes more prominent during periods of confinement. Appropriate management techniques consequently need to be implemented in intensive ostrich rearing systems, such as those used by slaughter bird producers, if aggression is to be reduced.

Generally, adult male ostriches are perceived to be more aggressive than females, especially in the presence of females (Sauer, 1972). It is unknown whether aggressive behaviour among juveniles follows a similar pattern, or even whether it is gender-related in adolescent individuals. Assuming that it is, we 
hypothesized that rearing juvenile males and females in single-sex groups might decrease agonistic behaviour, and consequently skin damage, amongst slaughter ostriches.

Separate-sex rearing is commonly employed in the poultry industry because of differences in growth rates and nutritional requirements of male and female chickens (Mine et al., 2002). Even though this practice is new to the ostrich industry, it may be beneficial since male and female ostriches also exhibit different growth rates (Deeming et al., 1993; Deeming \& Ayres, 1994; Mushi et al., 1998) and behavioural patterns (McKeegan \& Deeming, 1997; Deeming \& Bubier, 1999). Separate-sex rearing of slaughter ostriches was, therefore, investigated to determine the effect of gender and specifically gender composition on the behaviour of juvenile ostriches, and consequently on skin quality at slaughter.

\section{Materials and Methods}

The study was carried out from October 2000 to April 2002 at the Klein Karoo Agricultural Development Centre near Oudtshoorn, South Africa. Experimental birds used in the study were African Black ostriches (Struthio camelus domesticus), which were part of the commercial flock maintained at the research station.

The chicks were reared to three months of age in a combination of concrete brooder pens and lucerne camps, after which the chicks were maintained in feedlot paddocks that are mostly devoid of vegetation. At six months of age they were moved to a secluded location where behavioural observations could take place undisturbed. The ostriches had visual contact with each other and were weighed and rotated through the paddocks monthly. A concentrated food ration and drinking water were provided throughout and standard management practices, as described by Bunter (2002), were implemented.

The chicks were weighed and identified soon after hatching. Gender was determined by cloacal sexing of the day-old chicks since ostriches are morphologically identical up to about 12 months of age when the adult plumage starts to appear (Deeming et al., 1996). Cloacal sexing involves physical examination of the genitalia, which are everted from the cloaca by applying pressure on either side of the cloaca in a gentle kneading motion (Minnaar, 1998). This technique was proven highly successful, with an accuracy of approximately $95 \%$ obtainable with sufficient experience (Deeming et al., 1996).

The trial comprised of three blocks. Each block consisted of chicks hatched during two consecutive weeks. Within blocks, chicks were randomly sorted according to gender (mixed-gender, all-male and allfemale). This regime resulted in nine experimental units, each consisting of a group of chicks. Group sizes ranged from 64 to 80 at this stage. At three months of age, each of these experimental units was sorted according to weight into a low weight group and a high weight group, resulting in 18 experimental units. Each of the gender treatments was thus represented by six replications, while the weight class treatments were each represented by nine replications. Because sorting into groups according to weight was done at three months of age, mortality for each treatment was calculated to three months of age, which is the critical period for chick survival.

Behavioural data were collected from the treatment groups at nine and 13 months of age, respectively, to enable comparisons across age-sex classes. Because ostriches are mostly inactive at night (Degen et al., 1989; Lambrechts \& Cloete, 1998), observations were limited to daylight hours. Observations were carried out in close proximity (20-30 metres from the nearest paddock) from behind a stationary hide to which the ostriches had become accustomed. A period of about 10 minutes was allowed between positioning of the observer behind the hide and the start of observations. Observation periods of two hours average duration were spread over all daylight hours to encompass two days per block. The onset of observation sessions was scheduled at predetermined times, with observations starting 30 minutes before sunrise and ending 30 minutes after sunset, approximately.

The range of behaviours exhibited was determined during preliminary observations. Behaviours of importance were identified and pooled to obtain six predominant categories of behaviour that were subsequently recorded. The categories of behaviour that were differentiated were: inactive (standing, sitting or lying down), locomotive (walking, running or twirling), ingestive (feeding or drinking), ground pecking, comfort behaviour (object pecking, preening or dust bathing) and aggression (threat displays, chasing, chest ramming, kicking or trampling).

Diurnal time-activity budgets for treatment groups were established by means of instantaneous scan sampling (Altmann, 1974) of all birds in each paddock. Six groups (one block) were observed during each observation period and scan samples were taken alternately for each of the groups at five-minute intervals, thereby scanning each group once every half-hour. Each scan sample was taken within less than one minute 
and the rest of the time was used to observe all the groups for incidents of agonistic behaviour. Agonistic behaviour, as defined by McGlone (1986), was recorded by means of all occurrence sampling (Altmann, 1974; Lehner, 1992). The categories of agonistic behaviour that were recorded are defined in Table 1.

The number of birds participating in each of the behavioural categories was recorded on a check sheet at the predetermined sampling intervals, while all occurrences of agonistic behaviour were noted on a separate check sheet. Quantitative weather data, treatment, group size and time of day were recorded accordingly. Data were later pooled to obtain means per hour for each treatment.

Table 1 Categories of agonistic behaviour that were recorded during observation of control (mixed-gender) groups and single-sex (all-male and all-female) groups of slaughter ostriches

\begin{tabular}{ll}
\hline Agonistic behaviour & Definition \\
\hline Hiss / beak gapes & Opening beak wide either producing no sound or producing a hiss-like sound \\
Threat display & Standing with tail erect, hissing, feathers puffed and wings open \\
Chase & Chasing a bird away without running after it, causing it to flee, retreat or react \\
Run-chase & Chasing another bird by running after it \\
Chest ramming & Two birds ramming into each other with chests held high \\
Kicking / trampling & Kicking legs forward and up in an attempt to kick another bird or standing over a sitting \\
& bird, trampling with feet on the sitting bird's back and sides \\
Mounting & A bird attempts to mount another bird by sitting down on top of it \\
\hline
\end{tabular}

At 14 months of age the treatment groups were transported to a commercial abattoir located about five $\mathrm{km}$ from the farm. Delivery of the respective blocks to the abattoir was different at each slaughter date. Block one was driven to the abattoir on foot and block two was transported by lorry. Block three was also transported by lorry, but each ostrich was fitted with an overcoat to protect their skins during transportation. Any variation that could be attributed to the transportation method was confounded with the block and could be accounted for by considering block effects.

Chest circumference, slaughter weight, carcass weight, gender, skin weight, skin area and skin grading were recorded at slaughter. Grading of the raw skins was done by the Klein Karoo Co-operative's grading personnel through subjective evaluation of the crown area for visible damage. The crown is defined as the area on an ostrich's back that is covered by quill follicles and damage in this area determines skin grading. The number, location and type of damage (i.e. scratches, kick marks, chafe marks, sun damage, eaten feathers and bacterial damage, as defined by the grading personnel) on the rest of the skin were also identified and noted. The total number of lesions on, respectively, the crown area, the area outside of the crown, and the entire skin, was subsequently derived.

Paddock means were derived from averages of the individual ostriches belonging to a specific experimental unit (13-18 ostriches per unit/group at slaughter). The model used to analyze the data contained the effects of block, gender treatment (mixed, all-male, all-female), and weight class treatment (high weight or low weight), as specified previously. Blocks were included for the reduction in the total sums of squares offered. The interaction between gender treatment and weight class treatment was also computed. The general ANOVA is presented in Table 2. The interactions of block with the other fixed effects and the threefactor interaction were used as error term to discern significant differences in other effects.

Table 2 Analysis of variance table for the general model employed

\begin{tabular}{lc}
\hline Source of variation & Degrees of freedom \\
\hline Blocks & $3-1=2$ \\
Gender treatment & $3-1=2$ \\
Weight class treatment & $2-1=1$ \\
Gender treatment X weight class treatment & $(3-1)^{*}(2-1)=2$ \\
Remainder & 10 \\
Total & $18-1=17$ \\
\hline
\end{tabular}

The same basic principles were used in the analysis of the behavioural data. Time of observation was added to the time-activity budget data as an additional factor to the analysis. The overall occurrences of agonistic behaviour were totaled for each paddock, and divided by the number of birds in the paddock. In 
this way, an indication of the mean number of agonistic interactions per bird was obtained on a per paddock basis. Main effect means were tabulated in all analyses. Significant differences between treatment means were detected using the least significant difference method, provided that it was protected by a significant Fvalue in the ANOVA table (Snedecor \& Cochran, 1967). In cases where significant interactions were found between the gender and weight treatments, these were noted in the text.

\section{Results}

The gender of the ostriches was confirmed at slaughter by examination of the carcasses for either ovaries or testes. For the 283 birds that were eventually slaughtered, cloacal sexing of the day-old chicks was shown to have been $97.5 \%$ accurate. Sexing errors were randomly distributed throughout the treatment groups, and are therefore not taken into account for the remainder of the discussion.

The mean monthly weights of chicks in the experimental groups are given in Table 3 . The weight of ostriches in groups sorted for low weight was consistently lower $(\mathrm{P}<0.01)$ than that of ostriches in groups sorted for high weight, with correspondingly smaller carcasses at slaughter $(\mathrm{P}<0.01)$.

Table 3 Mean monthly weights $(\mathrm{kg})$ of groups of slaughter ostriches based on gender treatment or weight classification

\begin{tabular}{cccccccc}
\hline \multirow{2}{*}{ Trait } & \multicolumn{4}{c}{ Gender treatment } & \multicolumn{3}{c}{ Weight classification } \\
\cline { 2 - 7 } & Mixed & Male & Female & s.e. mean & Low weight & High weight & s.e. mean \\
\hline $\begin{array}{c}\text { Number of observations } \\
\text { Age (months) }\end{array}$ & 6 & 6 & 6 & & 9 & 9 & \\
3 & 15.7 & 15.8 & 14.7 & 0.5 & $12.3^{1}$ & $18.6^{2}$ & 0.3 \\
4 & 24.0 & 24.9 & 24.0 & 0.6 & $18.8^{1}$ & $29.8^{2}$ & 0.4 \\
5 & 33.2 & 33.8 & 32.7 & 0.8 & $26.3^{1}$ & $40.2^{2}$ & 0.5 \\
6 & 41.9 & 41.9 & 41.4 & 0.9 & $33.7^{1}$ & $49.8^{2}$ & 0.6 \\
7 & 52.7 & 52.1 & 52.1 & 1.2 & $43.8^{1}$ & $60.7^{2}$ & 0.7 \\
8 & 60.8 & 61.7 & 62.3 & 1.3 & $53.4^{1}$ & $69.7^{2}$ & 0.8 \\
9 & 69.5 & 70.7 & 70.1 & 1.5 & $62.2^{1}$ & $78.0^{2}$ & 0.9 \\
10 & 77.2 & 77.9 & 77.4 & 1.5 & $69.4^{1}$ & $85.6^{2}$ & 0.9 \\
11 & 84.6 & 84.9 & 85.0 & 1.6 & $77.1^{1}$ & $92.6^{2}$ & 1.0 \\
14 & 96.2 & 93.9 & 95.8 & 1.7 & $89.0^{1}$ & $101.5^{2}$ & 1.0 \\
\hline
\end{tabular}

Within rows, within treatment tested, ${ }^{1,2}$ denote significant differences $(\mathrm{P} \leq 0.01)$

There was no evidence of differences in the monthly weights of the groups separated on gender. Mortality to three months of age was also not influenced by gender treatment, as were the slaughter traits (Table 4). The only difference was for skin weight without fat $(\mathrm{P}<0.05)$, where the all-male groups had heavier skins than all-female groups. The high weight groups had larger $(\mathrm{P}<0.01)$ and heavier $(\mathrm{P}<0.01)$ skins than the low weight groups. The only slaughter parameters not influenced by weight classification were chest circumference and skin grading (Table 4). No evidence of an interaction between gender treatment and sorting according to weight was found.

Significantly more lesions indicative of kick marks were found outside the crown area of the skins in the all-male groups than in the mixed-gender groups $(\mathrm{P}<0.05$; Table 5$)$. There was also a tendency $(\mathrm{P}=$ $0.07)$ for the all-male groups to have more lesions in the crown area that were indicative of illnesses and ingrown feathers than the all-female groups. Scratch lesions $(\mathrm{P}=0.09)$ and overall lesions outside the crown area $(\mathrm{P}=0.06)$ also tended to be more prevalent in the all-male groups than in the all-female groups. These differences, however, only approached significance.

Overall lesions resulting from kick marks were affected $(\mathrm{P}<0.05)$ by an interaction of gender treatment with weight class treatment. No significant differences between gender groups were found in low weight groups $(0.389$ for mixed-gender groups, 0.192 for all-male groups and 0.296 for all-female groups; s.e. mean $=0.132)$. In contrast, in high weight groups, overall kick marks were more prevalent $(\mathrm{P}<0.05)$ in all-male groups (1.035) compared to mixed-gender groups (0.494) and all-female groups (0.693).

Kick marks in the crown area tended to be more prevalent in the high weight groups than in the low weight groups (Table 5), although the difference only approached significance $(\mathrm{P}=0.07)$. Kick marks in the area outside of the crown and for the total skin area were significantly higher in the high weight groups than 
in the low weight groups $(\mathrm{P}<0.05$; Table 5). No other significant differences between weight class treatments were found.

Table 4 Mean slaughter parameters in groups of slaughter ostriches based on gender treatment or weight classification

\begin{tabular}{lccccccc}
\hline \multirow{2}{*}{ Trait } & \multicolumn{4}{c}{ Gender treatment } & \multicolumn{3}{c}{ Weight classification } \\
\cline { 2 - 8 } & Mixed & Male & Female & s.e. mean & Low weight & High weight & s.e. mean \\
\hline Number of observations & 6 & 6 & 6 & & 9 & 9 & \\
Mortality to 90 days (proportions)* & 0.445 & 0.448 & 0.454 & 0.015 & & & \\
Slaughter weight, after bleeding (kg) & 89.3 & 88.5 & 87.5 & 1.7 & $82.8^{1}$ & $94.1^{2}$ & 1.4 \\
Chest circumference (cm) & 111.3 & 110.2 & 109.5 & 1.8 & 109.6 & 11.1 & 1.4 \\
Carcass weight (kg) & 42.7 & 43.3 & 43.4 & 1.1 & $40.2^{1}$ & $46.1^{2}$ & 0.9 \\
Skin weight (kg): & & & & & & & \\
With fat & 7.36 & 7.71 & 7.48 & 0.24 & $6.56^{1}$ & $8.47^{2}$ & 0.19 \\
Without fat & $4.53^{\mathrm{a}, \mathrm{b}}$ & $4.83^{\mathrm{b}}$ & $4.37^{\mathrm{a}}$ & 0.10 & $4.17^{1}$ & $4.98^{2}$ & 0.08 \\
Skin area (dm²) & 136.8 & 136.2 & 137.2 & 1.2 & $133.0^{1}$ & $140.4^{2}$ & 1.0 \\
Skin grading (proportions) & & & & & & & \\
Grade 1 & 0.465 & 0.367 & 0.419 & 0.074 & 0.491 & 0.343 & 0.085 \\
Grade 2 & 0.356 & 0.452 & 0.385 & 0.047 & 0.350 & 0.445 & 0.054 \\
Grade 3 & 0.178 & 0.181 & 0.185 & 0.045 & 0.155 & 0.209 & 0.051 \\
\hline
\end{tabular}

Within rows, within "Gender treatment", ${ }^{\mathrm{a}, \mathrm{b}}$ denote significant differences $(\mathrm{P} \leq 0.05)$

Within rows, within "Weight classification", ${ }^{1,2}$ denote significant differences $(\mathrm{P} \leq 0.01)$

* Based on three experimental units per gender treatment, since data were recorded prior to weight classification

Table 5 Mean number of lesions per bird in groups of slaughter ostriches based on gender treatment or weight classification

\begin{tabular}{|c|c|c|c|c|c|c|c|}
\hline \multirow[t]{2}{*}{ Trait } & \multicolumn{4}{|c|}{ Gender treatment } & \multicolumn{3}{|c|}{ Weight classification } \\
\hline & Mixed & Male & Female & s.e. mean & Low weight & High weight & s.e. mean \\
\hline Number of observations & 6 & 6 & 6 & & 9 & 9 & \\
\hline Crown area: & & & & & & & \\
\hline Kick marks & 0.271 & 0.201 & 0.215 & 0.058 & 0.112 & 0.346 & 0.067 \\
\hline Scratches & 1.806 & 1.974 & 2.135 & 0.209 & 1.673 & 1.837 & 0.241 \\
\hline Sunburn & 0.101 & 0.021 & 0.158 & 0.066 & 0.104 & 0.082 & 0.076 \\
\hline Chafe marks & 0.009 & 0.011 & 0.010 & 0.009 & 0.032 & 0.001 & 0.011 \\
\hline Illnesses, ingrown feathers & 0.093 & 0.236 & 0.113 & 0.041 & 0.129 & 0.165 & 0.047 \\
\hline Total & 2.280 & 2.443 & 1.980 & 0.221 & 2.050 & 2.418 & 0.255 \\
\hline Outside crown: & & & & & & & \\
\hline Kick marks & $0.171^{\mathrm{a}}$ & $0.413^{\mathrm{b}}$ & $0.280^{\mathrm{a}, \mathrm{b}}$ & 0.045 & $0.180^{\mathrm{a}}$ & $0.395^{\mathrm{a}}$ & 0.052 \\
\hline Scratches & 0.195 & 0.299 & 0.052 & 0.071 & 0.171 & 0.194 & 0.082 \\
\hline Total & 0.443 & 0.791 & 0.452 & 0.101 & 0.454 & 0.671 & 0.117 \\
\hline Overall: & & & & & & & \\
\hline Kick marks & 0.442 & 0.614 & 0.495 & 0.081 & $0.292^{\mathrm{a}}$ & $0.741^{\mathrm{b}}$ & 0.093 \\
\hline Scratches & 2.002 & 2.273 & 1.536 & 0.236 & 1.843 & 2.031 & 0.272 \\
\hline Total & 2.724 & 3.235 & 2.431 & 0.266 & 2.504 & 3.089 & 0.308 \\
\hline
\end{tabular}

Within rows, within treatment tested, ${ }^{\mathrm{a}, \mathrm{b}}$ denote significant differences $(\mathrm{P} \leq 0.05)$

There were no significant differences in the overall proportion of time spent on most routine activities in the mixed-gender or same-sex groups of ostriches (Table 6). Agonistic behaviour, however, was more prevalent in the all-male groups than in the all-female and mixed-gender groups $(\mathrm{P}<0.05)$. Overall, the high weight groups spent more time inactive and on aggressive interactions and less time on ingestion than the low weight groups (Table 6). For ground pecking and comfort behaviour, weight class treatment interacted with age at observation. Low weight groups spent a higher percentage of their time ground pecking at nine months $(16.6 \%$ vs. $12.5 \%$; s.e. mean $=0.7 ; \mathrm{P}<0.01)$. No significant difference was found at 13 months $(14.4 \% v$ s. $13.7 \%$; s.e. mean $=0.7)$. At nine months of age high weight groups spent a higher percentage of their time on comfort behaviour $(10.0 \% v s .9 .0 \%$ respectively; s.e. mean $=0.4 ; \mathrm{P}<0.05)$. A difference in the opposite direction was found at 13 months $(9.4 \%$ vs. $10.9 \%$ respectively; s.e. mean $=0.04 ; \mathrm{P}<0.05)$. 
Agonistic interactions were generally more common in the all-male groups than in the other groups (Table 7). Only a tendency $(\mathrm{P}=0.06)$ to this effect was found in the occurrence of hissing, but all three groups differed significantly in levels of threat displays and chasing $(\mathrm{P}<0.01)$. The all-male groups exhibited the most threat and chase behaviour and the all-female groups the least. Kicking and mounting were also more prevalent in the all-male group than in mixed-gender and all-female groups $(\mathrm{P}<0.05)$.

Table 6 Mean time-activity budgets (\%) of groups of slaughter ostriches based on gender treatment or weight classification, when combined for observations at nine and 13 months of age

\begin{tabular}{lccccccc}
\hline Age and activity & \multicolumn{3}{c}{ Gender treatment } & \multicolumn{3}{c}{ Weight classification } \\
\cline { 2 - 8 } & Mixed & Male & Female & s.e. mean & Low weight & High weight & s.e. mean \\
\hline Number of observations & 184 & 184 & 184 & & 276 & 276 & \\
Inactive & 42.7 & 41.4 & 43.9 & 1.0 & $40.9^{1}$ & $44.4^{2}$ & 0.8 \\
Locomotive & 14.7 & 15.6 & 14.1 & 0.5 & 14.6 & 14.9 & 0.6 \\
Ingestive & 18.6 & 17.6 & 17.1 & 0.6 & $18.5^{\mathrm{b}}$ & $17.0^{\mathrm{a}}$ & 0.5 \\
Ground pecking & 13.5 & 14.4 & 15.0 & 0.6 & $15.5^{2}$ & $13.1^{1}$ & 0.5 \\
Comfort behaviour & 9.9 & 10.1 & 9.4 & 0.4 & 10.0 & 9.7 & 0.3 \\
Aggressive & $0.60^{\mathrm{a}}$ & $0.96^{\mathrm{b}}$ & $0.53^{\mathrm{a}}$ & 0.10 & $0.58^{\mathrm{a}}$ & $0.81^{\mathrm{b}}$ & 0.08 \\
\hline
\end{tabular}

Within row, within treatment tested, ${ }^{\mathrm{a}, \mathrm{b}}$ denote significant differences $(\mathrm{P} \leq 0.05)$

Within row, within treatment tested, ${ }^{1,2}$ denote significant differences $(\mathrm{P} \leq 0.01)$

When the agonistic categories were combined, all three groups differed for threat behaviours (hiss and threat displays) and locomotive aggressive behaviours (chase and run-chase) $(\mathrm{P}<0.01)$. Physical aggression (chest ramming, kicking or trampling and mounting) was more prevalent in the all-male groups than in the all-female groups $(\mathrm{P}<0.05)$.

Agonistic behaviours were generally more prevalent in the high weight groups than in the low weight groups $(\mathrm{P}<0.05$; Table 7). These differences were carried through to threat behaviour. Corresponding tendencies were found for locomotive $(\mathrm{P}=0.06)$ and physical aggression $(\mathrm{P}=0.09)$ but differences only approached significance.

Table 7 Mean occurrences of agonistic behaviour in groups of juvenile ostriches based on gender or weight class treatment

\begin{tabular}{lccccccc}
\hline \multirow{2}{*}{ Agonistic behaviour } & \multicolumn{4}{c}{ Gender treatment } & \multicolumn{3}{c}{ Weight classification } \\
\cline { 2 - 7 } & Mixed & Male & Female & s.e. mean & Low weight & High weight & s.e. mean \\
\hline Number of observations & 6 & 6 & 6 & & 9 & 9 & \\
Individual patterns: & & & & & & & \\
Hiss & 2.623 & 3.924 & 1.831 & 0.535 & 2.580 & 3.005 & 0.436 \\
Threat display & $2.856^{2}$ & $4.914^{3}$ & $1.760^{1}$ & 0.329 & $2.291^{1}$ & $4.062^{2}$ & 0.279 \\
Chase & $3.225^{2}$ & $5.123^{3}$ & $1.760^{1}$ & 0.561 & $2.567^{\mathrm{a}}$ & $4.162^{\mathrm{b}}$ & 0.458 \\
Run chase & 1.110 & 2.351 & 0.493 & 0.232 & 1.211 & 1.425 & 0.189 \\
Chest ramming & 0.184 & 0.228 & 0.060 & 0.061 & $0.069^{\mathrm{a}}$ & $0.246^{\mathrm{b}}$ & 0.050 \\
Kick & $0.505^{\mathrm{a}, \mathrm{b}}$ & $0.874^{\mathrm{b}}$ & $0.154^{\mathrm{a}}$ & 0.149 & 0.387 & 0.635 & 0.121 \\
Mount & $0.032^{\mathrm{a}, \mathrm{b}}$ & $0.133^{\mathrm{b}}$ & $0.010^{\mathrm{a}}$ & 0.028 & 0.070 & 0.046 & 0.023 \\
Combined patterns: & & & & & & & \\
Threat & $5.479^{2}$ & $8.839^{3}$ & $3.591^{1}$ & 0.778 & $4.872^{\mathrm{a}}$ & $7.067^{\mathrm{b}}$ & 0.636 \\
Locomotive & $4.334^{2}$ & $7.474^{3}$ & $2.254^{1}$ & 0.734 & 3.787 & 5.587 & 0.599 \\
Physical & $0.721^{\mathrm{a}, \mathrm{b}}$ & $1.235^{\mathrm{b}}$ & $0.225^{\mathrm{a}}$ & 0.187 & 0.526 & 0.927 & 0.153 \\
\hline
\end{tabular}

Within row, within treatment tested, ${ }^{\mathrm{a}, \mathrm{b}}$ denote significant differences $(\mathrm{P} \leq 0.05)$

Within row, within treatment tested, ${ }^{1,2,3}$ denote significant differences $(\mathrm{P} \leq 0.01)$

\section{Discussion}

Considerable variation in the weight of ostrich chicks within younger age classes allowed for the separation of the birds into two weight classes at three months of age. Initial differences in weight persisted until slaughter. This is in agreement with previously observed high coefficients of variation in ostrich weight (Bunter \& Graser, 2000; Cloete et al., 2001). 
Skin size was larger in the high weight groups than in the low weight groups, confirming an economically important correlation between slaughter weight and skin size (Meyer et al., 2002b). While slaughter age also exerts an important influence on various slaughter traits (Meyer et al., 2002b), it seems that slaughter weight has an equally important influence on slaughter and physical traits, since ostriches that were compared, were of the same age.

Separate-sex rearing had no influence on mortality or growth. Live weight and slaughter traits were also largely unaffected by gender, indicating that ostriches, unlike most other domestic species, exhibit little sexual dimorphism up to slaughter age. The only slaughter trait that was affected by gender treatment was skin weight without fat, where all-male groups had significantly heavier skins than all-female groups. This is consistent with results reported by Van Schalkwyk et al. (1999), which showed male skins to be $10 \%$ heavier than those of females. The skin area and the weight of the skins with subcutaneous fat did not differ, indicating that males probably have thicker skins than females. This contention is supported by results published by Van Schalkwyk et al. (2002) who found that leather from male ostriches had a higher average thickness compared to leather from females.

Skin grading, as done for economic purposes, was largely unaffected by gender treatment. However, when visible skin lesions on the entire skin were evaluated, significant treatment differences did become evident. For the area outside the crown, there were more kick marks in all-male groups than in all-female groups and mixed-gender. This could either be due to increased aggression between males in all-male groups, or to kicking being a gender-specific behaviour. The mixed-gender group, however, had the fewest kick marks, indicating that kicking is not a male-only behaviour. It seems, therefore, that males are more aggressive when reared in single-sex groups, which is supported by the generally higher incidence of aggression observed in all-male groups.

In the crown area scratches remain the most important cause of skin damage. Except for a tendency towards more scratches in the area outside of the crown in all-male groups, the incidence of scratches was largely unaffected by separate-sex rearing. The tendency towards more scratches on male skins in the area outside of the crown would conform to previous suggestions that scratches probably originate from kicking injuries at a young age or from other claw injuries of a less severe nature (Meyer et al., 2002a). These would include young chicks climbing on each other when cold or running over each other during stress situations. Such injuries are not gender-related and would be located mostly in the crown area of the skin due to the nature of injury infliction. In contrast, kick marks at a young age appear to be responsible for the tendency towards more scratches on the skin outside of the crown area.

In groups classed according to weight, kick marks were more prevalent on the skins of the high weight groups, indicating that heavier birds become aggressive before birds of the same age with lower weights. The onset of aggression in young animals is influenced by sex hormones (Craig, 1986). Ostriches usually become aggressive at about 11 to 13 months of age, at the onset of puberty (Angel, 1996; Samson, 1996; Nicol et al., 1999). Hormone levels of other domestic animals are related to growth or weight (Scaramuzzi \& Campbell, 1990; Smith \& Stewart, 1990). Weight, and not age, is therefore probably the main factor that determines the onset of puberty and aggression through its influence on hormone levels, and specifically testosterone, which regulates avian aggression (Hau et al., 1999). This is supported by the interaction of gender treatment with weight class treatment for overall kick marks on the entire skin, where kick marks were more prevalent in all-male groups selected for high weight, but not in all-male groups selected for low weight.

Behaviour, as examined by diurnal time-activity budgets for the treatment groups, indicated that gender differences were generally absent in nonbreeding ostriches. The only behavioural categories that were influenced by aggressive behaviour, which was more prevalent in all-male groups, and locomotive behaviour. Males spent significantly more time on locomotive behaviour at 13 months of age. This could be related to pacing, which is a common territorial behaviour in breeding males, and would therefore increase as males approach sexual maturity. This indicates that the onset of puberty and related behaviour changes is nearer to 13 months of age.

Weight class treatment had a more pronounced effect on general behaviour than gender composition. The high weight groups were generally more inactive, more aggressive, and spent less time at ingestive behaviours than the low weight groups. The increased aggression that was observed corresponds with the skin damage observed on the skins in these groups. At nine months of age, the low weight groups spent more time engaged in ground pecking and less time on comfort behaviour than the high weight groups. This could be indicative of higher stress levels in the low weight groups (Huchzermeyer, 1997). 
When agonistic behaviour was evaluated it became clear that the all-male groups exhibited more agonistic behaviour than the other groups, and particularly the all-female groups. It is widely accepted that testosterone triggers aggressive behaviour in males of many vertebrate species, and that males are therefore generally more aggressive than females. Craig (1986) also indicated that once dominance hierarchies are established in groups of animals, they tend to be stable in female groups but less so in male groups, as was supported by our results.

In juvenile ostriches aromatase (an androgen-metabolizing enzyme) probably also plays an important role in aggression. The role of aromatase in aggression has only recently been acknowledged, especially in year-round aggression when plasma testosterone levels vary, and in castrated males (Archawaranon \& Wiley, 1988; Schlinger \& Callard, 1989; Soma \& Wingfield, 1999; Soma et al., 1999; Hau et al., 1999). Therefore, female aggressiveness may also be related to aromatase levels rather than to testosterone levels, which are generally low in females.

Mounting was observed significantly more in the all-male groups than in the all-female or mixed groups. It was originally recorded as an agonistic behaviour category due to its possible relevance to skin damage, but whether it should be interpreted as such is debatable. Aberrant sexual behaviour (e.g. male-tomale kantling) has also been reported in groups of male ostriches in Namibia and was explained as either suppressed aggression or as a means of releasing sexual tension (Sauer, 1972). The presumably close link between sexual and agonistic behaviour justified its inclusion as an agonistic behaviour. The mounting observed during this study did not include other elements of normal courtship behaviour, which was seen during homosexual behaviour among adult males (Sauer, 1972), and it can therefore be interpreted as aggression rather than sexual behaviour.

Males were furthermore more prone to physical aggression, which is supported by Bolwig (1973) who stated that aggressive behaviour often took on a more violent character in male ostriches than in females. Threatening and locomotive aggressive acts were also more prevalent in all-male groups. The all-female groups were the least aggressive of all the treatment groups.

Similar patterns were observed in the poultry inductry. When Leonard et al. (1993) investigated the effect of separate-sex rearing on sexual and agonistic behaviour in poultry they found that males in mixedgender groups displayed significantly more sexual behaviour than those in single-sex male groups. Males in single-sex groups were, however, significantly more aggressive than males in mixed-gender groups, which indicated a negative correlation between aggression and sexual behaviour in poultry.

In addition, laying hens exhibited agonistic behaviour more frequently in single-sex groups than in mixed groups (Odén et al., 1999). This was attributed to an apparent reducing effect that the presence of males in mixed groups had on female aggressiveness. It is possible that the decrease in aggression among male ostriches in mixed-gender groups can be attributed to a similar effect of the presence of female ostriches on male aggressiveness.

\section{Conclusion}

Behavioural data correlated well with skin damage data. Although some important gender-related differences in behaviour were found, it did not justify the use of separate-sex rearing to minimize skin damage of slaughter ostriches, since the low levels of aggression in all-female groups are cancelled out by the increased aggression in all-male groups. Raising females in single-sex groups to decrease aggression is considered impractical because of the sex ratio of approximately 1:1 for ostriches. Therefore, although this study provided valuable information regarding gender-specific differences for slaughter ostriches, it failed to produce a viable solution for the high prevalence of damage on ostrich skins. It also questions the importance of aggression and kicking behaviour regarding final skin grading. Skin damage in the economically important crown area of the skin is mostly attributed to scratch marks, and separate-sex rearing did not decrease these. More research is needed to generate a better understanding of the factors that cause skin damage to assist us in finding viable alternative solutions for preventing these lesions.

\section{Acknowledgements}

We thank the Klein Karoo Co-operative for financial assistance and co-operation during data collection at the abattoir and tannery. We also express our gratitude to the technical and other staff of the Klein Karoo Agricultural Development Centre for their support in the execution of the project. Finally, we gratefully acknowledge the role of the Animal Production Research Trust and Department of Agriculture of the Western Cape for making this project possible. 


\section{References}

Altmann, J., 1974. Observational study of behaviour: sampling methods. Behaviour 49, 227-267.

Angel, R., 1996. On-farm management to improve product quality. American Ostrich Association, Fort Worth.

Archawaranon, M. \& Wiley, R., 1988. Control of aggression and dominance in white-throated sparrows by testosterone and its metabolites. Horm. Behav. 22, 497-517.

Bolwig, N., 1973. Agonistic and sexual behaviour of the African ostrich (Struthio camelus). Condor 75, 100-105.

Bunter, K.L., 2002. The genetic analysis of reproduction and production traits recorded for farmed ostriches (Struthio camelus). Ph.D. thesis, University of New England, Australia.

Bunter, K. \& Graser, H., 2000. Genetic evaluation for Australian ostriches. A report for the Rural Industries Research and Development Corporation, RIRDC Publication No 00/, Project No UNE.57A.

Cloete, S.W.P., Lambrechts, H., Punt, K. \& Brand, Z., 2001. Factors related to high levels of ostrich chick mortality to 90 days in an intensive rearing system. J. S. Afr. Vet. Assoc. 72, 197-202.

Craig, J.V., 1986. Measuring social behavior: social dominance. J. Anim. Sci. 62, 1120-1129.

Deeming, D.C. \& Ayres, L., 1994. Factors affecting the rate of growth of ostrich (Struthio camelus) chicks in captivity. Vet. Rec. 135, 617-622.

Deeming, D.C., Ayres, L. \& Ayres, F.J., 1993. Observations on the commercial production of ostrich (Struthio camelus) eggs in the United Kingdom: rearing of chicks. Vet. Rec. 132, 627-631.

Deeming, D.C. \& Bubier, N.E., 1999. Behaviour in natural and captive environments. In: The Ostrich: Biology, Production and Health. Ed. Deeming, D.C., CAB International.

Deeming, D.C., Dick, A.C.K. \& Ayres, L.L., 1996. Ostrich chick rearing: a stockman's guide. Ratite Conf., Banbury. p. 24.

Degen, A.A., Kam, M. \& Rosenstrauch, A., 1989. Time-activity budget of ostriches (Struthio camelus) offered concentrate feed and maintained in outdoor pens. Appl. Anim. Behav. Sci. 22, 347-358.

Hau, M., Wikelski, M., Soma, K. \& Wingfield, J., 1999. Testosterone and year-round territorial aggression in a tropical bird. Gen. Comp. Endocrinol. 117, 20-33.

Huchzermeyer, F.W., 1997. Behaviour problems in farmed birds. Ostrich News 4, 17-21.

Lambrechts, H. \& Cloete, S.W.P., 1998. Activity budgets of adult breeding ostriches classified according to annual egg production of the previous breeding season. Proc. $36^{\text {th }}$ Nat. Congr. S. Afr. Soc. Anim. Sci., April 1998, University of Stellenbosch. pp. 93-94.

Lehner, P.H., 1992. Sampling methods in behavior research. Poult. Sci. 71, 643-649.

Leonard, M.L., Zanette, L. \& Fairfull, W., 1993. Early exposure to females affects interactions between male White Leghorn chickens. Appl. Anim. Behav. Sci. 36, 29-38.

McGlone, J.J., 1986. Agonistic behaviour in food animals: review of research and techniques. J. Anim. Sci. 62, 1130-1139.

McKeegan, D.E.F. \& Deeming, D.C., 1997. Effects of gender and group size on the time-activity budgets of adult breeding ostriches (Struthio camelus) in a farming environment. Appl. Anim. Behav. Sci. 51, 159-177.

Meyer, A., Cloete, S.W.P., Brown, C.R. \& van Schalkwyk, S.J., 2002a. Declawing ostrich (Struthio camelus domesticus) chicks to minimize skin damage during rearing. S. Afr. J. Anim. Sci. 32, 192-200.

Meyer, A., Cloete, S.W.P., Bunter, K.L., Van Schalkwyk, S.J. \& Brand, Z., 2002b. Genetic parameters for live weight and skin traits in ostriches. Proc. $1^{\text {st }}$ Joint Congr., Grassl. Soc. S. Afr. \& S. Afr. Soc. Anim. Sci., 13-16 May, Christiana, South Africa. p. 82.

Meyer, A., Cloete, S.W.P., Brown, C.R. \& van Schalkwyk, S.J., 2003. The persistence to slaughter age of scars resulting from damage to ostrich skins during the grow-out phase. S. Afr. J. Anim. Sci. 33, 3237.

Mine, O.M., Mochakana, M.E., Mpapho, T., Motlhanka, D.T.M. \& Kgwatalala, P., 2002. Application of a sex identification technique in juvenile ostriches and its potential application in Botswana. S. Afr. J. Anim. Sci. 32, 160-163.

Minnaar, M., 1998. The Emu Farmer's Handbook. Vol. 2. Nyoni Publ. Co., USA. pp. 165-166.

Mushi, E.Z., Isa, J.F.W., Chabo, R.G. \& Segaise, T.T., 1998. Growth rate of ostrich (Struthio camelus) chicks under intensive management in Botswana, Trop. Anim. Health Prod. 30, 197-203. 
Nicol, C.J., Gregory, N.G., Knowles, T.G., Parkman, I.D. \& Wilkins, L.J., 1999. Differential effects of increased stocking density, mediated by increased flock size, on feather pecking and aggression in laying hens. Appl. Anim. Behav. Sci. 65, 137-152.

Odén, K., Vestergaard, K.S. \& Algers, B., 1999. Agonistic behaviour and featherpecking in single-sexed and mixed groups of laying hens. Appl. Anim. Behav. Sci. 62, 219-231.

Sales, J., 1999. Slaughter and Products. In: The Ostrich: Biology, Production and Health. Ed. Deeming, D.C., CAB International.

Samson, J., 1996. Behavioural problems of farmed ostriches in Canada. Can. Vet. J. 37, 412-414.

Sauer, E.G.F., 1972. Aberrant sexual behavior in the African ostrich. Auk 89, 717-737.

Scaramuzzi, R.J. \& Campbell, B.K., 1990. Physiological regulation of ovulation rate in the ewe: a new look at an old problem. In: Reproductive Physiology of Merino Sheep - Concepts and Consequences. School of Agriculture (Animal Science), The University of Western Australia, Perth 6009. pp. 71-84.

Schlinger, B.A. and Callard, G.V., 1989. Aromatase activity in quail brain: Correlation with aggressiveness. Endocrinology 124, 437-443.

Smith, J.F. \& Stewart, R.D., 1990. Effects of nutrition on the ovulation rate of ewes. In: Reproductive Physiology of Merino Sheep - Concepts and Consequences. School of Agriculture (Animal Science), The University of Western Australia, Perth 6009. pp. 85-101.

Snedecor, G.W. \& Cochran, W.G., 1967. Statistical methods. $6^{\text {th }}$ Edition. Iowa State University Press, Ames, Iowa, USA.

Soma, K.K., Sullivan K. \& Wingfield, J., 1999. Combined aromatase inhibitor and antiandrogen treatment decreases territorial aggression in a wild songbird during the nonbreeding season. Gen. Comp. Endocrinol. 115, 442-453.

Soma, K.K. \& Wingfield, J., 1999. Endocrinology of aggression in the nonbreeding season. In: "Proc. $22^{\text {nd }}$ Int. Ornithological Congr." Eds. Adams, N. \& Slotow, R., University of Natal, Durban.

Van Schalkwyk, S.J., Cloete, S.W.P., Hoffman, L.C., Brand, T.S., Meyer, A. \& Pfister, A.P., 2002. The effect of dietary energy and protein levels on skin size and physical leather parameters of ostriches. Proc. $1^{\text {st }}$ Joint Congr., Grassl. Soc. S. Afr. \& S. Afr. Soc. Anim. Sci., 13-16 May, Christiana, South Africa. p. 85.

Van Schalkwyk, S.J., Cloete, S.W.P. \& Lambrechts, H., 1999. Interrelationship between body weight, sex and skin measurements of slaughter ostriches in the Little Karoo Region. Proc. $37^{\text {th }}$ Nat. Congr. S. Afr. Soc. Anim. Sci., July 1999, Pretoria. p. 32. 